\title{
Characteristics of the particulate matter in Riyadh city, Saudi Arabia
}

\author{
A. S. Modaihsh and M. O. Mahjoub \\ Soil Science Department, College of Food Sciences and Agriculture, \\ King Saud University, Saudi Arabia
}

\begin{abstract}
Increased concern about the impact of the so-called particulate matter on air quality and public health has occurred in recent years. This concern is based on the increased knowledge on the impact the smallest particles have on human health. The primary goal of this study is to carry out a comprehensive characterization of Riyadh bio-aerosol and aerosol samples of PM1, and PM2.5 and provide the scientific background for the further control of air pollution at Riyadh and to develop effective strategies to reduce the ambient concentrations of PM and reduce the deposition of this pollutant to the city. Real time ambient air quality was monitored at Riyadh airport. Mass concentrations of PM2.5 and PM10 (particulate matter smaller than 2.5 and $10 \mu \mathrm{m}$ in diameter, respectively) for January-April were measured. The concentrations of coarse (PM10), and fine (PM2.5) particulate matter were measured using a Grimm model EDM 365 aerosol spectrometer. Measurement of particulate matter concentrations were obtained at time intervals ranging from $1 \mathrm{~s}$ to $60 \mathrm{~min}$. Measurement of particulates was done via laser-light scattering. The counts from each size classification are then converted to mass by a well-established equation. Results indicated that temporal variation observed either for PM10 or PM2.5. was associated mainly with the dust events. There is no significant temporal variation of influential metrological parameters. The ratio between PM10 and PM2.5 were found to be 0.25 . Statistical analysis has shown a strong positive correlation between them.
\end{abstract}

Keywords: PM10, PM2.5, dust storms, meteorological data, Saudi Arabia, Riyadh. 


\section{Introduction}

Due to the increased knowledge on the impact the smallest particles have on human health, recent years have witnessed a growing concern about the so-called particulate matter. Since 1997, research on air pollution count aerosols as one of the six major air pollutants (EPA [1]). Particulate matters have been divided according to their origin into natural and anthropogenic aerosols (Barry and Chorley [2]). The major sources of anthropogenic aerosols include fuel combustion from automobiles, power plants, wood burning, industrial processes, and diesel powered vehicles such as buses and trucks. Soil-derived (mineral) dust particles can be a major part of the atmospheric $\mathrm{PM}_{2.5}$ and $\mathrm{PM}_{10}$ concentrations (Sudheer and Rengarajan [3]). To address the issue of atmospheric particulate matter in Riyadh city, El-Shobokshy [4, 5] conducted his pioneering study on particulate pollution in Saudi Arabia, but his studies concentrated only on atmospheric lead pollution in the city of Riyadh. In 1990, El-Shobokshy et al. [6] investigated the influence of meteorology on the concentration of inhalable particulates which are usually observed in the atmosphere of Riyadh at high concentrations. However, the studies mentioned above were based on a limited number of samples.

No follow-up research to close the gap between the association of meteorological parameters, falling dust, Particulate matter concentration and health hazards has yet been performed. This is crucial if officials in the city are to develop strategies to reduce the impact of the deposition of Aeolian and ambient pollutants. This study aims to identify and quantify the source types contributing to ambient particulate matter, which is deposited within Riyadh.

\section{Methods}

Traditional method of $\mathrm{PM}_{10}$ dust measurement is based on a weight to volume measurement, where by the dust is collected on a filer and subsequently weighed. This method requires a rigid adherence to time consuming procedures. With the finer dust size fraction introduction $\left(\mathrm{PM}_{2.5}, \mathrm{PM}_{1}\right)$ the problem is negligible mass compared to the large numbers of these particles. For these reason a newly developed Aerosol Spectrometer will be introduced for measurement of various PM particulates.

In this study, the concentrations of coarse (PM10), and fine (PM2.5), particulate matter were measured using a Grimm model EDM 365 aerosol spectrometer (Grimm Aerosol Technik GmbH, Ainring, Germany). The device, an optical particle counter (OPC), is an instrument for real-time measurement of particulate matter. The particle size analyser/dust monitor determines the dustconcentration (counts/litre) through the optical-light-scattering method directly; however, the mass concentration is determined by extrapolation. The calculated mass concentration may be corrected to the specific aerosol measured with the gravimetric-correction factor (C-Factor). The advantages of this instrument over other real-time measurement instruments, such as TEOM or DMA devices, are its convenience, its low maintenance requirements, and its ability to run for long 
periods without specific supervision. The ability to measure particulate matter concentrations in time intervals ranging from $1 \mathrm{~s}$ to $60 \mathrm{~min}$ is considered to be another advantage offered by the instrument. The validity of the measurements performed by the instrument has been evaluated by several studies (Burkart et al. [7]). The dust monitor was installed on the roof of the Meteorology and Environmental building near Riyadh airport. The dust monitor ran 24 hours a day continuously.

\section{Results and discussion}

\subsection{Particulate mass concentration}

The concentrations of $\mathrm{PM}_{10}$, and $\mathrm{PM}_{2.5}$ were measured on 88 days from January $29^{\text {th }}$ through April 7th 2012. These measurement produced huge data and points for the concentration of $\mathrm{PM}_{10}$ and $\mathrm{PM}_{2.5}$, temperature and relative humidity data given for each week and covering this period. Figures 1-5 show the average daily concentration of $\mathrm{PM}_{10}$, and $\mathrm{PM}_{2.5}$ during different months of the study period. The overall mean value of $\mathrm{PM}_{10} \quad \mathrm{PM}_{2.5}$ were $563.37 \mu \mathrm{g} / \mathrm{m}^{3}$ and $141.66 \mu \mathrm{g} / \mathrm{m}^{3}$ respectively and the corresponding maximum values were $2371.23 \mu \mathrm{g} / \mathrm{m}^{3}$ and $640.8 \mu \mathrm{g} / \mathrm{m}^{3}$ and the corresponding minimum values were 91.6 and $21.49 \mu \mathrm{g} / \mathrm{m}^{3}$.

As shown in these figures, daily concentrations of both $\mathrm{PM}_{10}$ and $\mathrm{PM}_{2.5}$ measured at Riyadh airport were highly variable. Some very high concentrations (above 8000 and $2000 \mu \mathrm{g} / \mathrm{m}^{3}$ were occasionally measured for $\mathrm{PM}_{10}$, and $\mathrm{PM}_{2.5}$ respectively). The temporal variation observed either $\mathrm{PM}_{10}$ or $\mathrm{PM}_{2.5}$ was associated mainly with the dust events.

The results of $\mathrm{PM}_{10}$, and $\mathrm{PM}_{2.5}$ concentrations, obtained in this study are little higher than those found in other studies. Results obtained by studies of $\mathrm{PM}_{2.5}$ concentrations conducted in China by Ye et al. [8], reported a mean $\mathrm{PM}_{2.5}$ concentration of $67.6 \mu \mathrm{g} / \mathrm{m}^{3}$. Also He et al. [9] reported $89 \mu \mathrm{g} / \mathrm{m}^{3}$ during the spring. These values are little less than the values reported in this study. On the other hand some other studies reported more or less similar results. For an example $\mathrm{PM}_{10}$ concentrations higher than 3000 and produced by dust events were observed in a study conducted in Iraq, Kuwait and Saudi Arabia (Draxler et al. [10]). In contrast, Meng and Lu [11] observed mean $\mathrm{PM}_{2.5}$ concentrations of up to $216.7 \mu \mathrm{g} / \mathrm{m}^{3}$, which was higher than the results presented in this study (almost double). The explanation for this substantial difference is that the PM in the cited study is measured during winter months where fossil fuel combustions which considered as the primary source of fine particulate is highest In this study we observed that $\mathrm{PM}_{10}$ and $\mathrm{PM}_{2.5}$ concentrations mainly depend on dust storms occasions.

Our study clearly indicated that the hourly mean $\mathrm{PM}_{10}$ and $\mathrm{PM}_{2.5}$ concentration increased significantly during dust storms. Since there is no universally accepted definition of dust storms in terms of hourly dust concentrations, we arbitrary choose the criterion suggested by Park et al. [12] who identified dust events as the peak $\mathrm{PM}_{10}$ concentration exceeding one 
standard deviation of the annual mean concentration. Our criterion for dust storm events was an hourly mean $\mathrm{PM}_{10}$ concentration exceeding one standard deviation of the mean concentration during the study period (Mean $=563.37$ and standard deviation $=501.78 \mu \mathrm{g} / \mathrm{m}^{3}$ ). Based on this criterion, from Jan 29th to April 7th 2012, we identified 1, 9, 13, and 6 dust events at January, February, March and April respectively. In comparison, Chung et al. [13], defined dust storms in terms of measured $\mathrm{PM}_{10}$ concentration exceeds $190 \mu \mathrm{g} \mathrm{m}^{-3}$ for at least $2 \mathrm{~h}$.
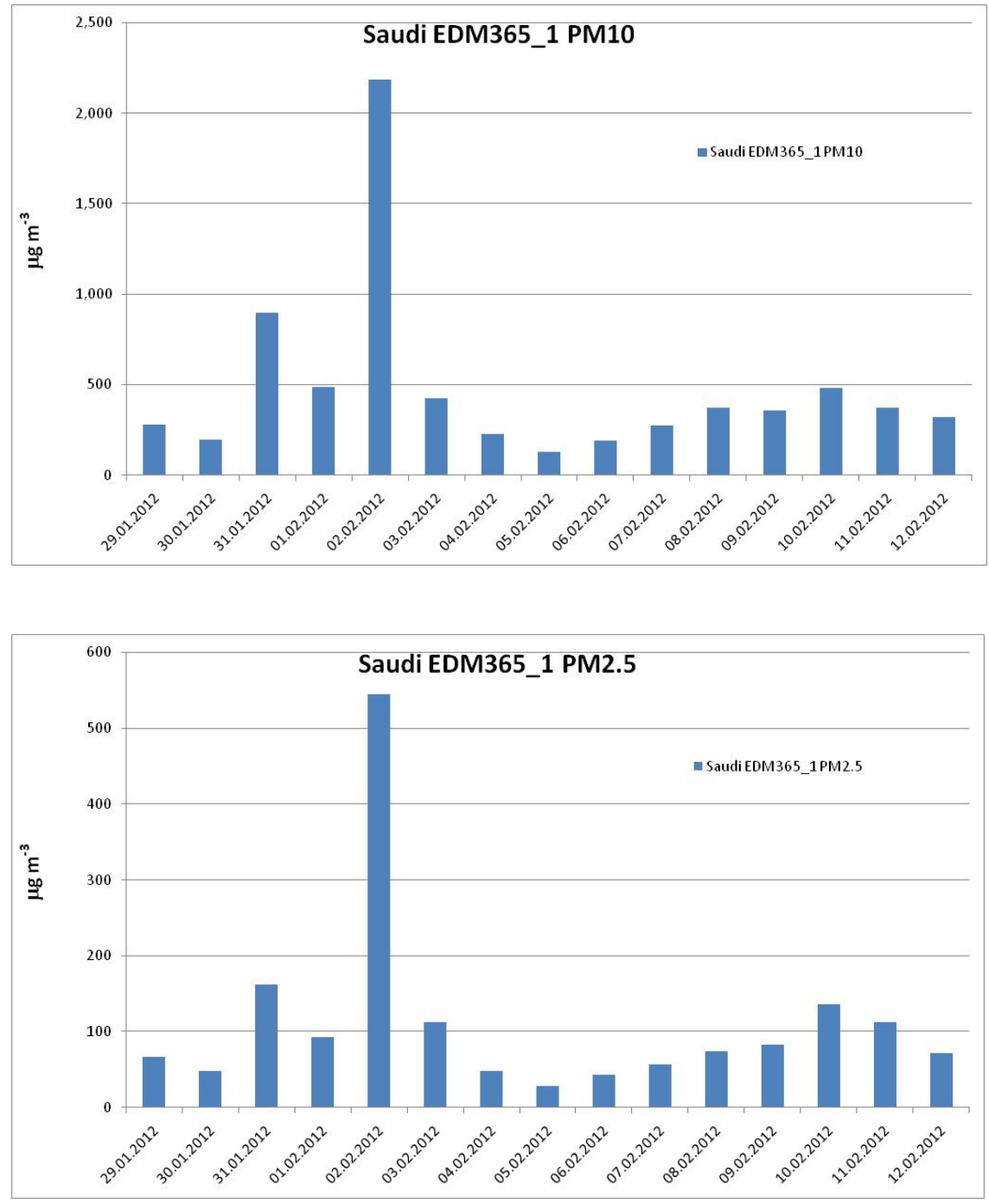

Figure 1: Daily 24-hour average $\mathrm{PM}_{10}$, and $\mathrm{PM}_{2.5}$ concentration $\mu \mathrm{g} / \mathrm{m}^{3}$ (29/1-12/2). 

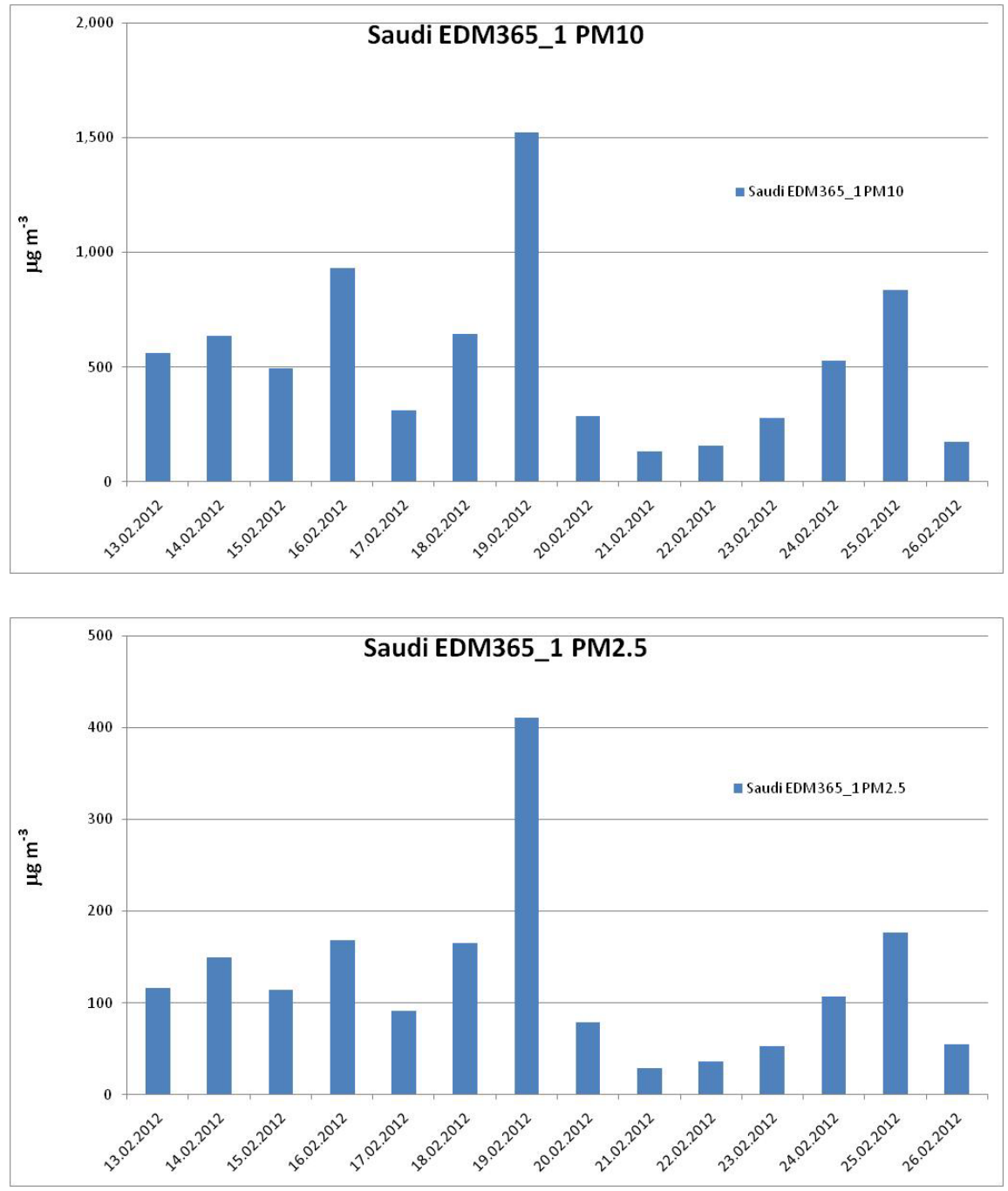

Figure 2: $\quad$ Average $\mathrm{PM}_{10}$, and $\mathrm{PM}_{2.5}$ concentration $\mu \mathrm{g} / \mathrm{m}^{3}(13 / 2-26 / 2)$.

\subsection{Relationships between $\mathbf{P M}_{10}, \mathbf{P M}_{2.5}$}

The ratios of $\mathrm{PM}_{10}$ and $\mathrm{PM}_{2.5}$ concentration data during 29/1/2011-26/04/2012 were analyzed. The obtained results showed that the ratios vary between 0.18 and 0.46 ). The ratios between monthly mean $\mathrm{PM}_{10}$ and $\mathrm{PM}_{2.5}$ concentrations in February was between 0.19 and 0.31 , in March were $0.18-0.45$ and $0.20-0.39$ in April. The daily averages of $\mathrm{PM}_{2.5} / \mathrm{PM}_{10}$, ratios over the study showed that a little decrease was observed in the dust days. The mean $\mathrm{PM}_{2.5} / \mathrm{PM} 10$ ratio for the entire study period was 0.25 . The mean values of these ratios during the dust days were 0.22 . 

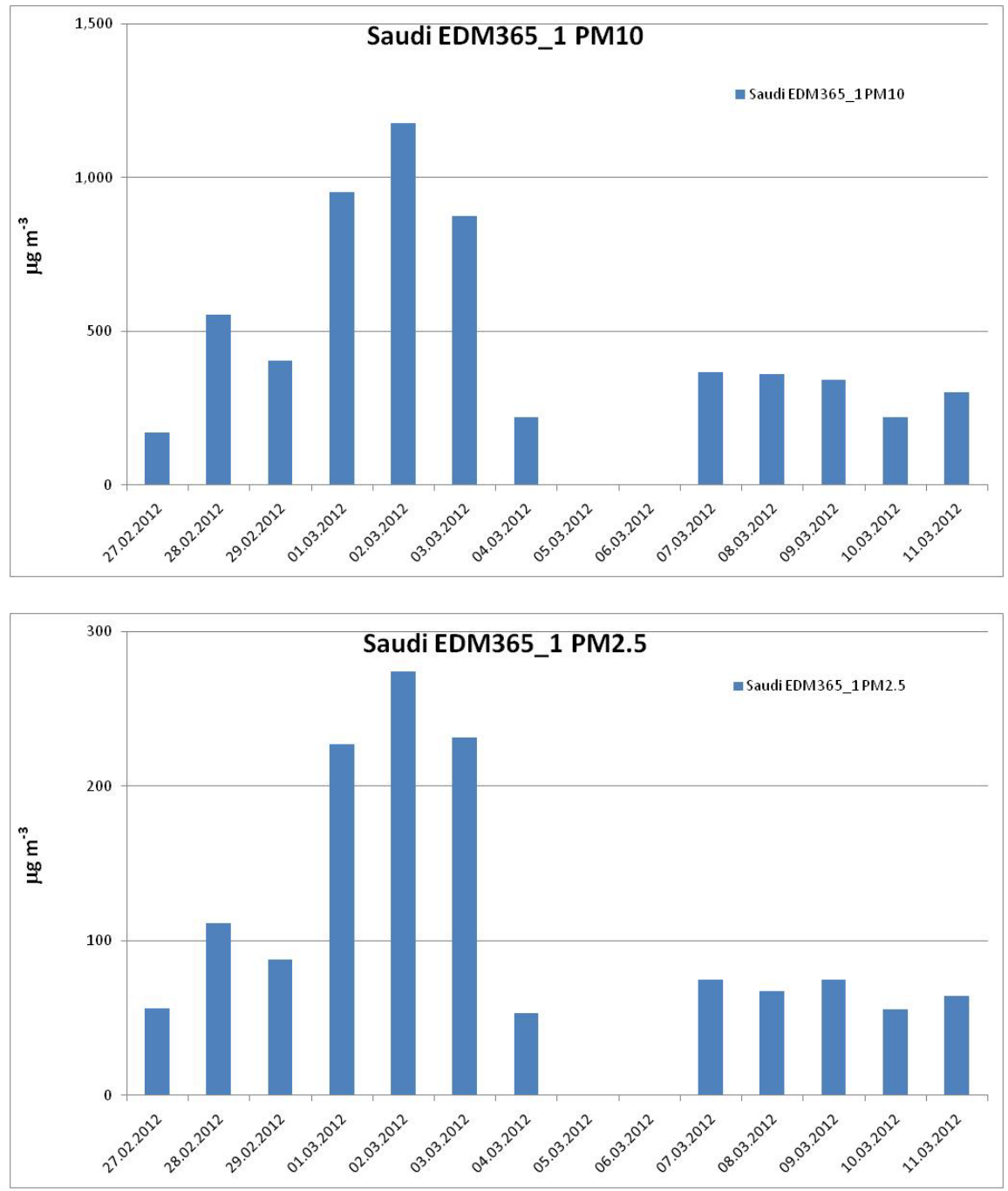

Figure 3: $\quad$ Average $\mathrm{PM}_{10}$, and $\mathrm{PM}_{2.5}$ concentration $\mu \mathrm{g} / \mathrm{m}^{3}(27 / 2-11 / 3)$.

The average $\mathrm{PM}_{2.5} / \mathrm{PM}_{10}$ ratio observed here is much lower than those found in other studies. For example, He et al. [9] reported a mean $\mathrm{PM}_{2.5} / \mathrm{PM}_{10}$ ratio of 0.64 for the entire study period. In addition, Ye et al. [8] reported a mean $\mathrm{PM}_{2.5}$ /TSP ratio of 0.55 for the entire study period. The primary reason for this difference is that in the two studies cited, the $\mathrm{PM}_{2.5} / \mathrm{PM}_{10}$ or $\mathrm{PM}_{2.5} / \mathrm{TSP}$ ratios were calculated for the entire year, including the autumn and winter. During these seasons, the fine fraction of particulate matter (i.e., $\mathrm{PM}_{2.5}$ ) is highest because various sources primarily release finer particles during these seasons and therefore produce an increase in the $\mathrm{PM}_{2.5} / \mathrm{PM}_{10}$ ratio. Accordingly, in the study of Ye et al. [8], the $\mathrm{PM}_{2.5}$ /TSP ratio in winter increased to 0.73 , whereas the ratio 
decreased to 0.35 in the late spring. In the present study, the $\mathrm{PM}_{2.5} / \mathrm{PM}_{10}$ ratio was the lowest during the dust events with slight increases in non-dust days. Therefore, these low ratios can be considered to represent dust events, the main component of which is expected to be coarse particles.
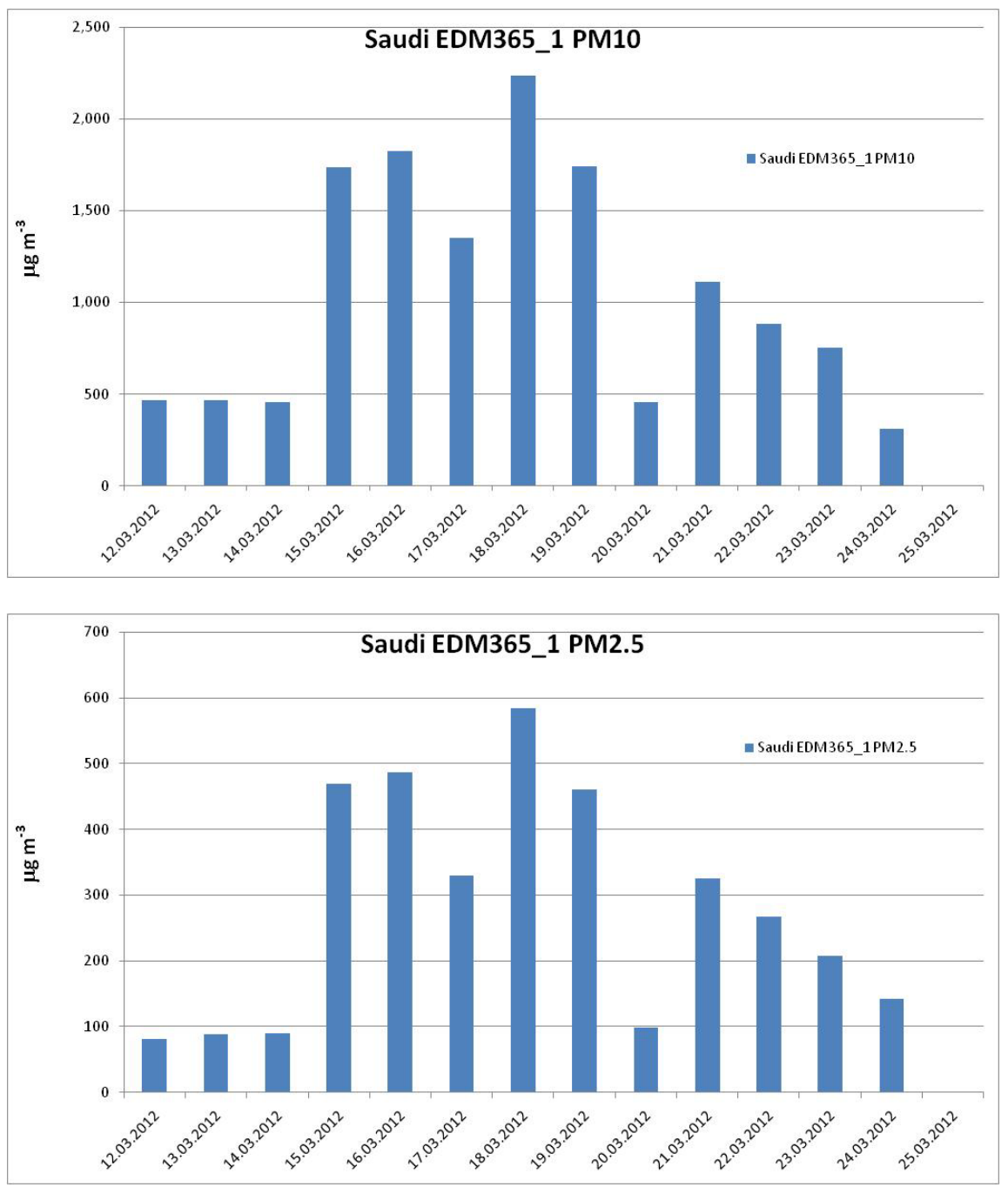

Figure 4: $\quad$ Average $\mathrm{PM}_{10}$, and $\mathrm{PM}_{2.5}$ concentration $\mu \mathrm{g} / \mathrm{m}^{3}$ (12/3-25/3). 

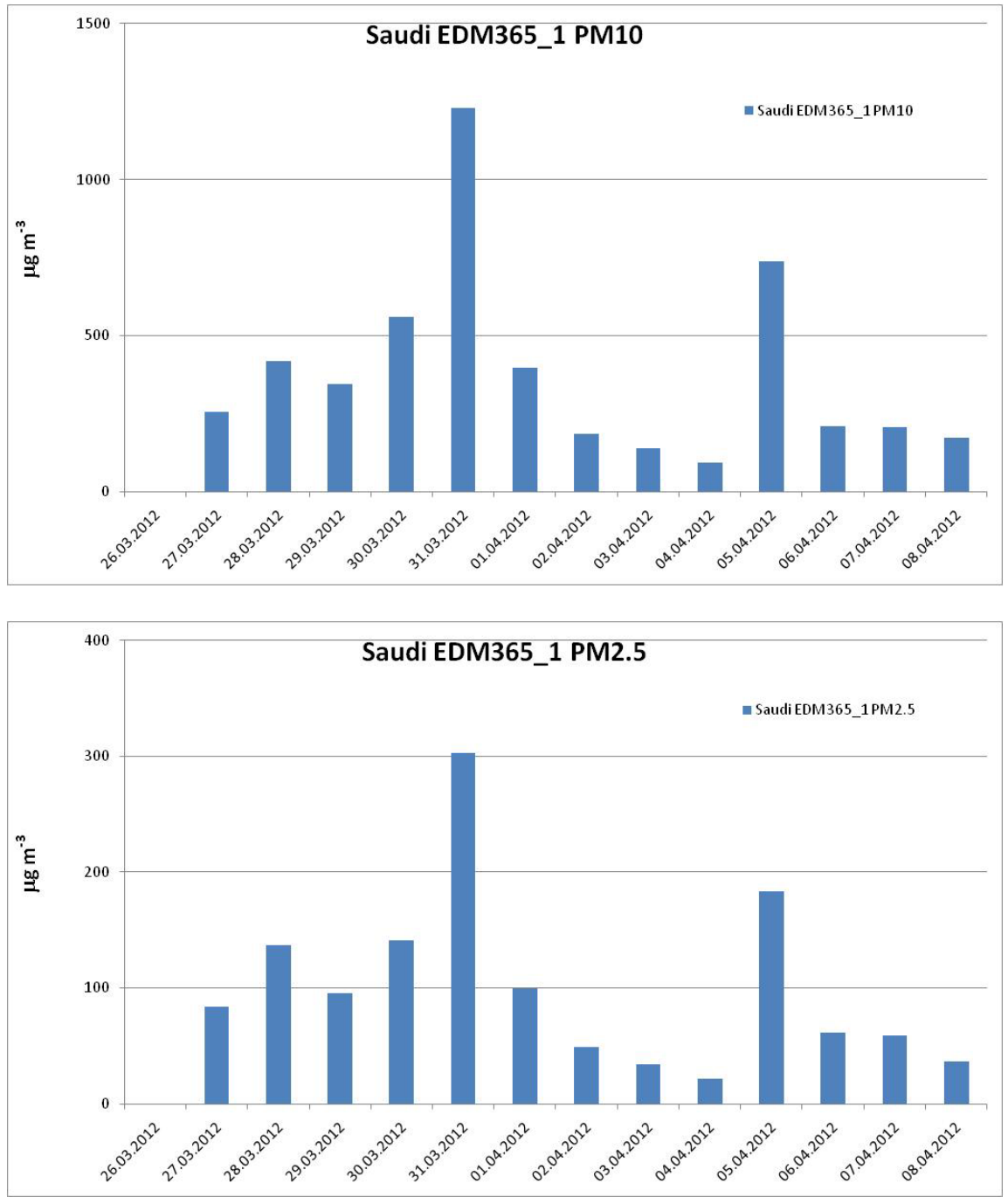

Figure 5: $\quad$ Average $\mathrm{PM}_{10}$, and $\mathrm{PM}_{2.5}$ concentration $\mu \mathrm{g} / \mathrm{m}^{3}(26 / 3-8 / 4)$.

\subsection{Influence of meteorological parameters on particulate matter}

The relationship between ambient particulate matter data and meteorological factors, such as temperature, relative humidity, was statistically analyzed. Table 1 shows the descriptive statistics of particulate matter and meteorological factors. Table 2 depicts the relationship between particle concentrations ( $\mathrm{PM}_{10}$ and $\mathrm{PM}_{2.5}$ ) and meteorological parameters (temperature, relative humidity). Very poor correlation was observed between particulate matters $\left(\mathrm{PM}_{10}, \mathrm{PM}_{2.5}\right)$ and meteorological parameters (temperature and relative humidity). The $\mathrm{PM}_{10}$ and $\mathrm{PM}_{2.5}$ is found to be strongly correlated with each other and inversely correlated 
with temperature with correlation coefficient of -0.43 and positively correlated with relative humidity, with a correlation coefficient of 0.28 .

Contrary to our results, several studies have confirmed the influence of meteorological conditions on PM concentrations (Giri et al. [14]; Kuang [15]). Atmospheric pressure, wind velocity temperature and humidity were found to be significant factors in influencing $\mathrm{PM}_{10}$. The present study demonstrated that temperature and relative humidity showed insignificant correlation to PM concentrations. This may be due to the fact that means of the whole day of PM on one hand and the average temperature humidity on the other hand might cancel the variation between night and day. Therefore, we selected different data in one day and split it between day and night hours to test the influence of temperature and humidity on PM concentrations. The obtained results depicted in table 3 showed the daily variation of $\mathrm{PM}_{10}$ and temperature during morning hours and evening hours separately in three different days. It was found that an inverse relationship exists between temperature and particulate data at relatively lower temperatures and a positive result with temperature and particulate matter exist under higher temperature. The correlation studies of the daily average of $\mathrm{PM}_{10}$ and $\mathrm{PM}_{2.5}$ concentration and various metrological factors at different seasons is needed to establish their relationship.

Table 1: Descriptive statistics of particulate matter and meteorological factors.

\begin{tabular}{|c|c|c|c|c|}
\hline \multirow{2}{*}{ Date } & \multicolumn{2}{|c|}{ Equation } & \multicolumn{2}{c|}{$\mathrm{r}^{2}$} \\
\cline { 2 - 5 } & Morning hours & Evening hours & Morning hours & Evening hours \\
\hline $31 / 1 / 2012$ & $\mathrm{y}=4.3483 \mathrm{x}^{0.2161}$ & $\mathrm{y}=3.215 \mathrm{x}^{0.2654}$ & 0.8493 & 0.7716 \\
\hline $29 / 2 / 2012$ & $\mathrm{y}=106.9 \mathrm{x}^{-0.282}$ & $\mathrm{y}=141.69 \mathrm{x}^{-0.335}$ & 0.8119 & 0.8349 \\
\hline $30 / 3 / 2012$ & $\mathrm{y}=55.532 \mathrm{x}^{-0.157}$ & $\mathrm{y}=61.708 \mathrm{x}^{-0.226}$ & 0.8075 & 0.5097 \\
\hline
\end{tabular}

Table 2: $\quad$ Spearman rank correlation coefficient of particulate data and meteorological factors.

\begin{tabular}{|l|l|l|l|l|l|}
\hline Parameters & Minimum & Maximum & Mean & Std. Deviation & $\mathbf{N}$ \\
\hline $\mathrm{PM}_{10}\left(\mu \mathrm{g} / \mathrm{m}^{3}\right)$ & 91.7 & 2371.2 & 563.37 & 501.78 & 88 \\
\hline $\mathrm{PM}_{2.5}\left(\mu \mathrm{g} / \mathrm{m}^{3}\right)$ & 21.5 & 640.8 & 141.66 & 131.86 & 88 \\
\hline TEMP. $\left({ }^{\circ} \mathrm{C}\right)$ & 10.4 & 28.8 & 19.92 & 4.93 & 88 \\
\hline $\mathrm{RH}(\%)$ & 9.10 & 61.9 & 31.65 & 12.68 & 88 \\
\hline
\end{tabular}

TEMP, RH, refers to temperature, relative humidity. Values were rounded to two decimal places. 
Table 3: Correlation coefficient of particulate data and meteorological factors.

\begin{tabular}{|c|c|c|c|c|}
\hline & $\mathbf{P M}_{\mathbf{1 0}}$ & $\mathbf{P M}_{2.5}$ & TEMP & RH \\
\hline $\mathrm{PM}_{10}$ & 1.000 & & & \\
\hline $\mathrm{PM}_{2.5}$ & $0.986^{* *}$ & 1.00 & & \\
\hline $\mathrm{TEMP}$ & -0.04 & -0.04 & 1.00 & \\
\hline $\mathrm{RH}$ & -0.29 & -0.58 & -0.16 & 1.00 \\
\hline
\end{tabular}

**Correlation is significant at .01 level.

\section{Acknowledgement}

The authors extend their thanks to the National Plan for Science and Technology Saudi Arabia for financial support of project \#08 ENV319-02 under the title "Characteristics and Composition of the Falling Dust and Particulate Matter and its Health Hazards in Riyadh City, Saudi Arabia”.

\section{References}

[1] EPA Air Trends- Criteria Pollutant. AIRNOW 2009.

[2] Barry, R. G. and Richard J. Chorley, Atmosphere, Weather and Climate, Routledge, New York, 2000.

[3] Sudheer, A. K and R. Rengarajan. Atmospheric Mineral Dust and Trace Metals over Urban Environment in Western India during Winter. Aerosol and Air Quality Research, 12: 923-933, 2012.

[4] El-Shobokshy, G. M. A primary analysis of inhalable particulate lead in the ambient atmosphere of the city of Riyadh. Saudi Arabia. Atmospheric Environment 18, 2125-2130, 1984.

[5] El-Shobokshy, G. M. Atmospheric lead pollution in areas of children schools in the city of Riyadh. $78^{\text {th }}$ Annual APCA Meeting, Detroit, Michigan, 16-21 June 1985.

[6] El-Shobokshy, M. S., Al-Tamrah, S. A. and Hussei, F. M. Inhalable particulates and meteorological characteristics of the city of Riyadh, Saudi Arabia. Atmospheric Environment, 24B (No 2): 261-265, 1990.

[7] Burkart, J. G. Steiner, G. Reischl H. Mashanmer and R. Hitzenberger. Characterizing the performance of two optical particle counters (Grimm OPC1. 108 and OPC1. 109) under urban aerosol conditions. J. Aerosol Sci. 41 (10) 953-962, 2010.

[8] Ye, B., J. Yang, H. Yao, Chan, C. K. Cadle, S. H. Chan, T. Mulawa, PA. Concentration and chemical composition of PM2.5 in Shanghai for a 1-year period. Atmospheric Environment 37, 499-510, 2003.

[9] He, K., Yang, F., Ma, Y., Zhang, Q., Yao, X., Chan, C. K., Cadle, S., Chan, T., Mulawa, P., 2001. The characteristics of PM2.5 in Beijing, China. Atmospheric Environment 35, 4959-4970.

[10] Draxler, R. R., Gillette, D. A., Kirkpatrick, J. S., Heller, J. Estimating PM10 air concentrations from dust storms in Iraq, Kuwait and Saudi Arabia. Atmospheric Environment 35, 4315-4330, 2001. 
[11] Meng, Z., Lu, B.,. Dust events as a risk factor for daily hospitalization for respiratory and cardiovascular diseases in Minqin, China. Atmospheric Environment 41, 7048-7058, 2007.

[12] Park, S. U., Park, M. S. and Chun, Y. A parameterization of dust concentration $\left(\mathrm{PM}_{10}\right)$ of dust events observed at Erdene in Mongolia using the monitored tower data, Science of the Total Environment 2951-2958, 2010.

[13] Chung, Y. S., Kim, K. S., Park, K. H., Jugder, D., Tao, G., Observations of dust storms in China, Mongolia and associated dust falls in Korea in spring 2003. Water, Air, and Soil Pollution, Focus, 5. Kluwer Academic Publishers, pp. 15-35, 2005.

[14] Giri, D., Krishna Murthy, V and Adhikary, P. R. The influence of meteorological conditions on PM10 concentrations in Kathmandu valley. Int. J. Environ. Res. 2(1): 1735-6865, 2008.

[15] Kuang, L. Y. Spatial and seasonal variation of PM10 mass concentrations in Taiwan. Atmospheric Environment, 36, 3403-3411, 2002. 